\title{
Chemical Tuning of Adsorption Properties of Titanate Nanotubes
}

\author{
Anastasia V. Grigorieva, ${ }^{1}$ Valentina V. Yuschenko, ${ }^{2}$ Irina I. Ivanova, ${ }^{2}$ \\ Eugene A. Goodilin, ${ }^{1,2}$ and Yuri D. Tretyakov ${ }^{1,2}$ \\ ${ }^{1}$ Faculty of Materials Science, Lomonosov Moscow State University, Leninskie Gory 1/3, Moscow 119992, Russia \\ ${ }^{2}$ Faculty of Chemistry, Lomonosov Moscow State University, Leninskie Gory 1/3, Moscow 119992, Russia
}

Correspondence should be addressed to Anastasia V. Grigorieva, anastasia@inorg.chem.msu.ru

Received 14 May 2012; Accepted 16 November 2012

Academic Editor: Jinquan Wei

Copyright (C) 2012 Anastasia V. Grigorieva et al. This is an open access article distributed under the Creative Commons Attribution License, which permits unrestricted use, distribution, and reproduction in any medium, provided the original work is properly cited.

\begin{abstract}
A conventional hydrothermal method widely used for the preparation of titania-based nanotubes still generates many unsolved questions. One of them is definitely connected with the influence of a posthydrothermal treatment of titania nanotubes on their micromorphology, structure, and adsorption characteristics. Here, it was analyzed systematically by a group of methods including nitrogen adsorption and temperature-programmed desorption of ammonia and carbon dioxide. It is proved that adsorption characteristics and the surface state of titania nanotubes correlate with a sodium content, since sodium ions act as Lewis acid sites and shield $\mathrm{Ti}^{4+}$ acid sites of the nanotubes. To obey a balance between chemical and heat treatments of the nanotubes to design their functional properties has been suggested.
\end{abstract}

\section{Introduction}

Nanostructured titanium dioxide materials promise a number of industrial and laboratory applications in electronics and medicine $[1,2]$. Titanium dioxide nanorods, nanotubes, nanoribbons, and nanosheets could be efficiently obtained via known chemical routes $[1,3]$. Obvious advantages of these materials have been shown in oxidative catalysis [3], chemical and UV-sensors [4], fuel cells [5], and lithium-ion batteries [6]. Titania-based nanostructures are effective as a support for highly dispersed metallic and oxide catalysts $[2,7]$ and photocatalysts $[8,9]$. Among all of them, titania nanotubes are important for catalysis because of their unique ability to develop particular surfaces with special active areas $[10,11]$. As reported elsewhere $[7,10,12,13]$, a specific surface area (BET area) of titania nanotubes varies from 50 to $400 \mathrm{~m}^{2} / \mathrm{g}$ depending on preparation conditions that is critical for efficiency of catalysis and other practical applications of such materials.

The nanotubes differ from the known crystalline forms of titania and titanates by both of their chemical composition and structure. Zhang et al. [14] considered Ti-O walls of the tubes to be isostructural to a trititanic acid $\mathrm{H}_{2} \mathrm{Ti}_{3} \mathrm{O}_{7}$, and Ti-O single layers are terminated by (001) planes of the titanate. Yang et al. [15] and Ma et al. [16] consider titania-based nanotubes to be titanates with lepidocrocitelike orthorhombic structure, while other authors suggest monoclinic structure [14, 17]. Probably, both hydrothermal and posthydrothermal treatment steps determine structure and composition of the nanotubes [2]. It is determined that titania nanotubes formation occurs during the hydrothermal processing [15] contrary to the idea of posthydrothermal scrolling of lamellar intermediate phases [13]. According to formation mechanisms suggested by $\mathrm{Wu}$ et al. [18], sodium cations play an important role being interframework cations of the sodium titanate precursor of the nanotubes. Mechanism of hydrothermal growth of scroll-like titanate nanostructures is detailed in [2].

An importance of a posthydrothermal treatment for titanate nanotubes has been recently reported by Tsai et al. $[13,17,19,20]$, since protonation and/or calcination give a way to vary the surface composition and thermal stability [9] and hence the functional properties of the material $[19,21]$. Tian et al. [22] succeeded to remove sodium cations from the interlayer spaces by treating with nitric, sulphuric, or hydrochloric acid. Organic acids also could be 


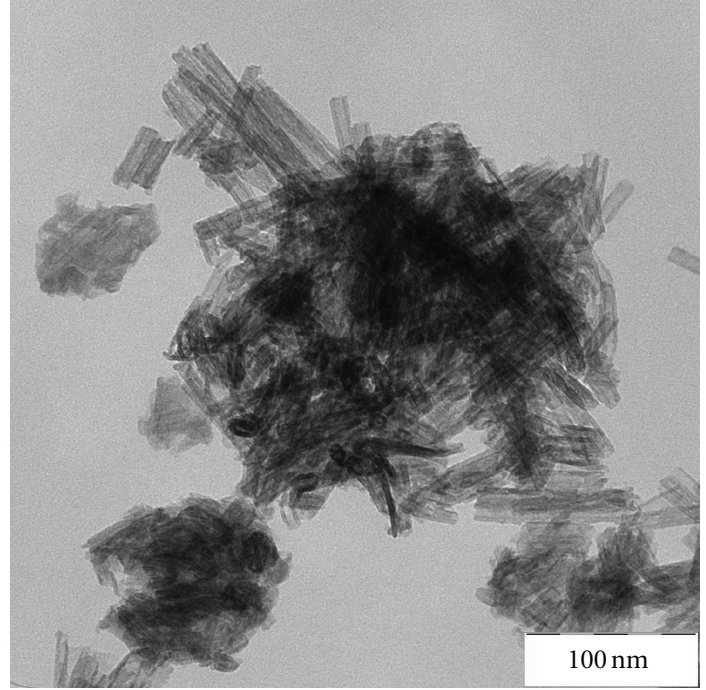

(a)

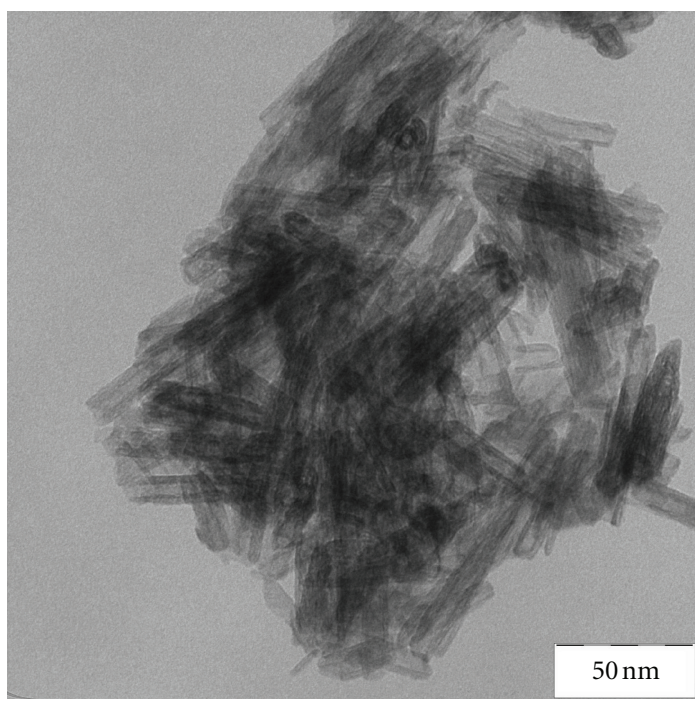

(b)

FIGURE 1: Typical micrographs of titanate nanotubes: (a) pristine (TNT10) and (b) ion-exchanged (TNT0).

TABLE 1: Chemical compositions and specific characteristics of surface of TNT $\mathrm{TiO}_{2-x} \cdot n \mathrm{H}_{2} \mathrm{O}$, sintered at $120^{\circ} \mathrm{C}, 200^{\circ} \mathrm{C}$, or $400^{\circ} \mathrm{C}$.

\begin{tabular}{lccccc}
\hline Sample & $\mathrm{Na}$, at $\%$ & $\omega\left(\mathrm{H}_{2} \mathrm{O}\right), \mathrm{w} \%$ & $n$ & $S_{\mathrm{BET}}, \mathrm{m}^{2} / \mathrm{g}$ & $92 \pm 10$ \\
\hline TNT10 & $10 \pm 1$ & 5.4 & 0.0 & 0.25 & $195 \pm 20$ \\
TNT0 & $0 \pm 0.5$ & 2.5 & 0.39 & $115 \pm 10$ & 0.29 \\
TNT10_200 & $10 \pm 1$ & 4.1 & 0.11 & $236 \pm 20$ & 0.48 \\
TNT0_200 & $0 \pm 0.5$ & 0.50 & 0.19 & $107 \pm 10$ & 0.75 \\
TNT10_400 & $10 \pm 1$ & 0.67 & 0.02 & $209 \pm 20$ \\
TNT0_400 & $0 \pm 0.5$ & & 0.03 & 0.32 \\
\hline
\end{tabular}

used for this purpose while they tend to modify the surface of nanotubes acting as surfactants [22]. Camposeco et al. [23] observed a phase transition of $\mathrm{H}_{2} \mathrm{~T}_{3} \mathrm{O}_{7}$ to $\mathrm{H}_{2} \mathrm{Ti}_{5} \mathrm{O}_{11}$ in nitric acid solution. Tsai and Teng [17] performed repeatable backwashing of the nanotubes with hydrochloric acid and sodium hydroxide to demonstrate evolution of microstructure depending on aggregation-disaggregation processes. However, it is not yet known if it is possible to remove sodium cations from the framework completely without degradation or phase transition of the tubular structure and, in general, how such a chemical treatment tunes the final functional properties of the nanotubes.

In the present study, acid/base characteristics have been analyzed by a group of adsorption techniques such as nitrogen physisorption, TPD of ammonia, and carbon dioxide to shed a light on the role of posthydrothermal processing on titanate nanotubes characteristics.

Microstructure of the pristine titania nanotubes (TNTs) is shown in Figure 1(a). The external diameter of the nanotubes is typically $9 \pm 1 \mathrm{~nm}$, while the internal diameter is of about $4 \mathrm{~nm}$. Each nanotube is formed by $3-5 \mathrm{TiO}_{6}$ layers, and the interlayer distance is about $7.2 \pm 0.5 \AA$ according to TEM data. The length of nanotubes varied in the range of $30-100 \mathrm{~nm}$. The nanotubes tend to form bundles, both shape and porosity of such aggregates varied depending on conditions of a posthydrothermal treatment. An acid treatment of the pristine material produces a rather stable dispersion in aqueous media.

Synthesis of titanate nanotubes was performed in alkali media, thus sodium cations could exist both at the external surfaces of the nanotubes and in the framework. Micrographs of the titanate nanotubes, pristine and protonated by nitric acid, show no significant degradation of tubular micromorphology of the particles (Figure 1(b)).

According to the EDS analysis, the pristine TNT (fraction TNT10) contained $10 \pm 1$ at $\%$ of sodium; while for the ion-exchanged nanotubes (TNT0) treated with a diluted nitric acid for 1 day and then washed by pure water, this percent was negligible (Table 1).

Analysis of XRD data (Figure 2(a)) demonstrated low crystallinity of both of the samples; the 001 reflections presented in the plots are broadened, perhaps as a result of a high curvature of Ti-O layers. We have not found any anatase reflections in XRD plots of the samples which means that the polycrystalline precursor is converted entirely. In the case of TNT10, the broad maxima could be referred to reflections of sodium trititanate $\mathrm{Na}_{2} \mathrm{Ti}_{3} \mathrm{O}_{7}$ (PDF2 entry no. 31-1329), while trititanate $\mathrm{H}_{2} \mathrm{Ti}_{3} \mathrm{O}_{7}$ (PDF2 entry no. 47-561) matches well. This result is in agreement with the known formation mechanism suggested by Miao et al. [21], 


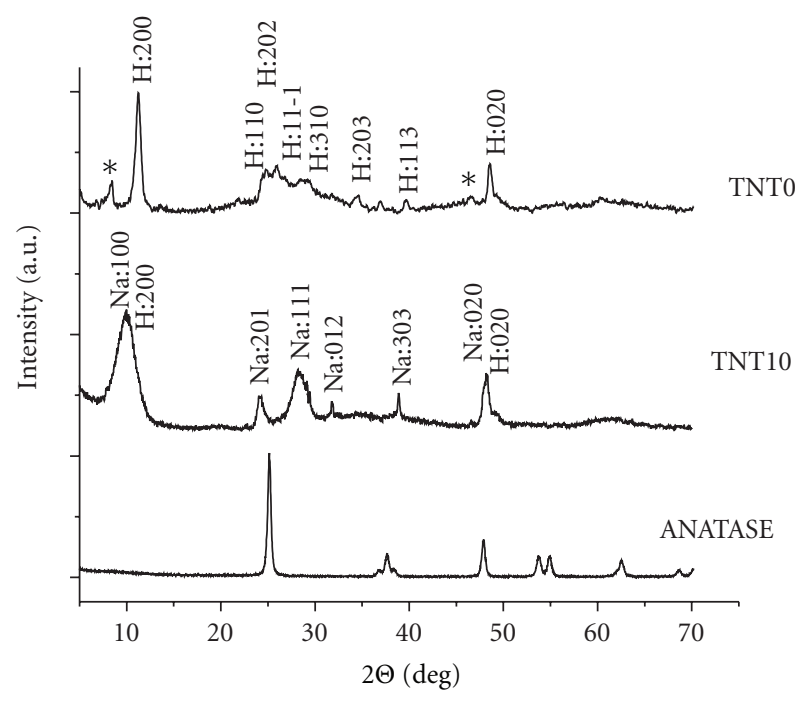

(a)

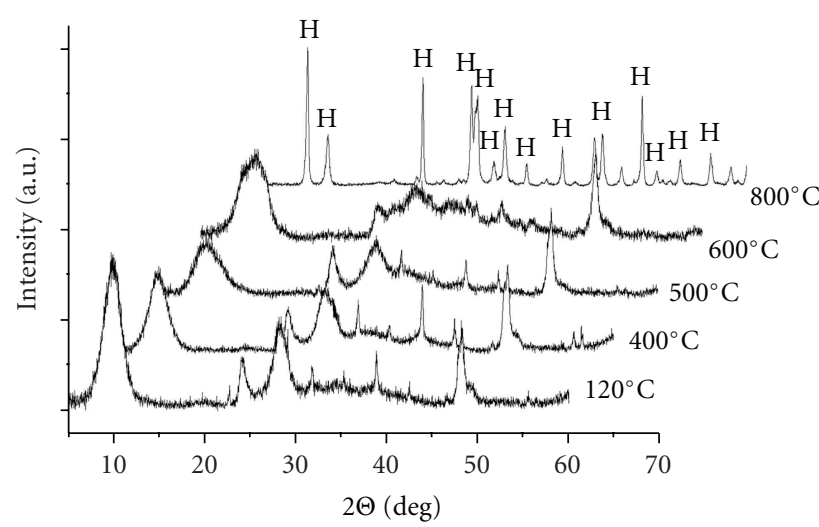

(c)

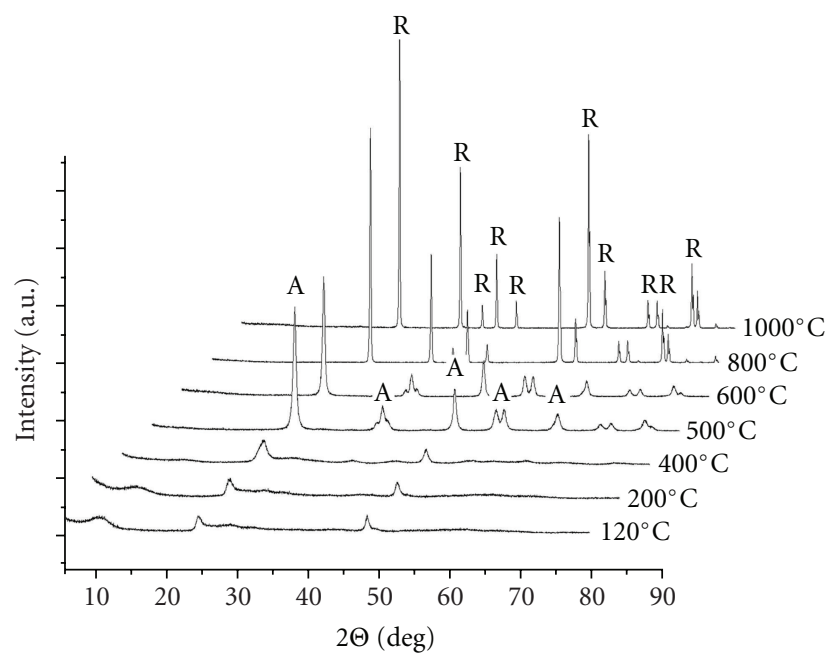

(b)

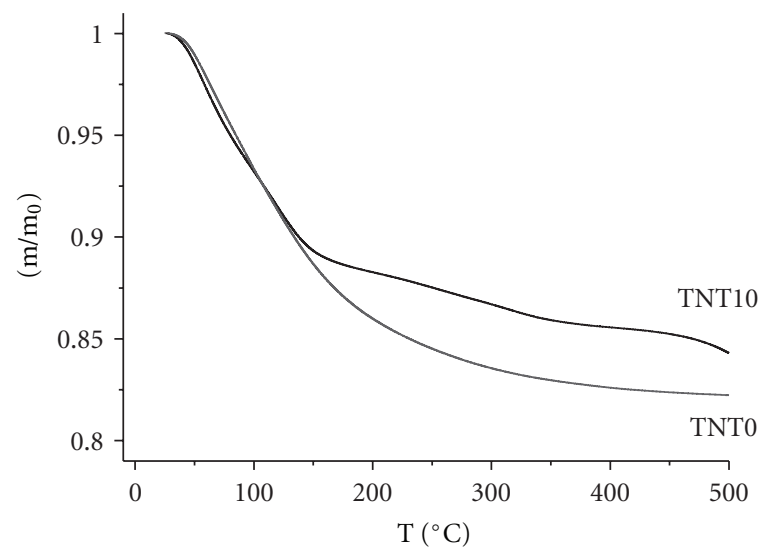

(d)

FIGURE 2: (a) XRD patterns of anatase (precursor), pristine nanotubes (TNT10), and ion-exchanged nanotubes (TNT0). H:hkl—trititanic acid $\mathrm{H}_{2} \mathrm{Ti}_{3} \mathrm{O}_{7}$ reflections; Na:hkl—sodium trititanate reflections; * reflections of hydrated pentatitanate $\mathrm{H}_{2} \mathrm{Ti}_{5} \mathrm{O}_{11} \cdot 3 \mathrm{H}_{2} \mathrm{O}$. (b) XRD data for the pristine nanotubes (TNT10) calcined for $12 \mathrm{~h}$ at different temperatures: $120^{\circ} \mathrm{C}, 400^{\circ} \mathrm{C}, 500^{\circ} \mathrm{C}, 600^{\circ} \mathrm{C}$, and $800^{\circ} \mathrm{C}$. (c) XRD data for ionexchanged TNT0 treated for $12 \mathrm{~h}$ at different temperatures: $120^{\circ} \mathrm{C}, 200^{\circ} \mathrm{C}, 400^{\circ} \mathrm{C}, 500^{\circ} \mathrm{C}, 600^{\circ} \mathrm{C}, 800^{\circ} \mathrm{C}$, and $1000^{\circ} \mathrm{C}$. (d) Thermogravimetric curves (TG) for titania nanotubes: pristine (TNT10) and ion-exchanged (TNT0).

according to which tubular structure is a result of scrolling of $(001) \mathrm{H}_{2} \mathrm{Ti}_{3} \mathrm{O}_{7}$ planes along the (100) direction. In the XRD plot of TNT0, the less intensive maxima at about $8.48^{\circ}$ and $48.50^{\circ}$ could be related to $(200)$ and $(020)$ reflections of hydrated pentatitanate $\mathrm{H}_{2} \mathrm{Ti}_{5} \mathrm{O}_{11} \cdot 3 \mathrm{H}_{2} \mathrm{O}$ (PDF2 file no. 44130) scrolled into a nanotube with preserving almost the same interplane distances. This agrees partly with the results reported in [23].

The XRD data show a significant difference between thermal degradation processes of the samples. In Figures 2(b) and 2(c), the XRD data are given for calcinated TNT10 and TNT0 nanotubes, respectively. Total thermal degradation of the pristine nanotubes TNT10 occurs at $550^{\circ} \mathrm{C}$ forming $\mathrm{Na}_{2} \mathrm{Ti}_{6} \mathrm{O}_{13}$ (PDF2 entry no. 73-1398) rod-like crystals that agrees with $[13,17]$. The ion-exchanged nanotubes TNT0 already turn completely to small crystallites of anatase at $500^{\circ} \mathrm{C}$.
The related thermogravimetric data given in Figure 2(d) demonstrate releasing absorbed water above $60^{\circ} \mathrm{C}$, and chemically bonded water is being lost upon heating up to $180^{\circ} \mathrm{C}$. In general, such behavior is typical for both of the materials. Initially TNT0 contained a higher amount of water ( $8 \mathrm{wt} \%$ to $5.4 \mathrm{wt} \%)$. During the calcination at $400^{\circ} \mathrm{C}$, the sample weights decreased up to $0.5 \mathrm{wt} \%$ and $0.67 \mathrm{wt} \%$ for TNT10_400 and TNT0_400, respectively. Above $470^{\circ} \mathrm{C}$, the TNT10 formed anhydrous hexatitanate $\mathrm{Na}_{2} \mathrm{Ti}_{6} \mathrm{O}_{13}$. The phase transition is accompanied by a release of interframework water, and, likely, the absence of an endothermic minimum is mimicked by a parallel strong exothermic effect of the recrystallization process.

Analysis of evolution of the nanotubes in ion-exchange process by adsorption techniques revealed a dependence of their surface characteristics on a sodium content. The BET 


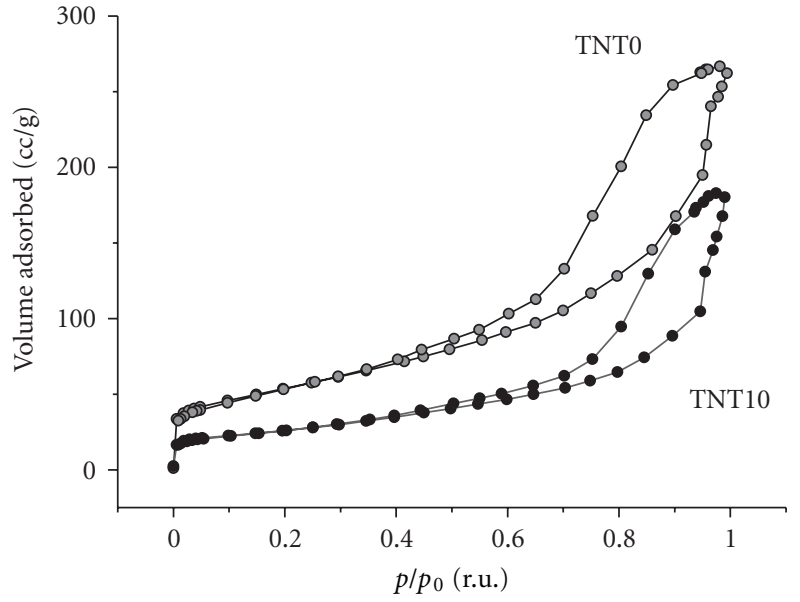

(a)

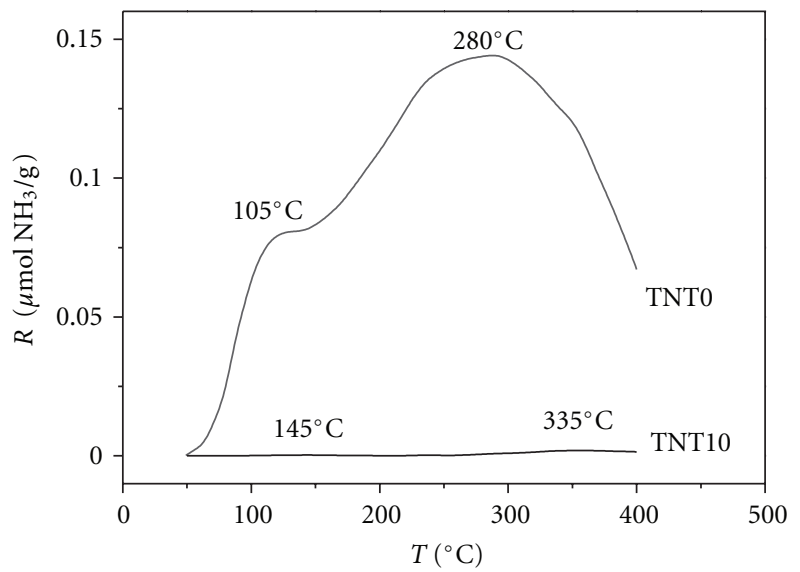

(c)

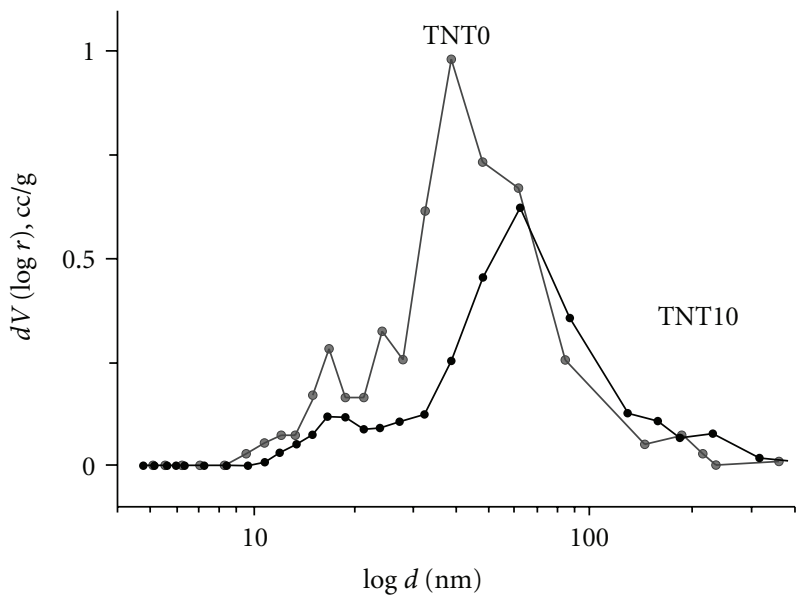

(b)

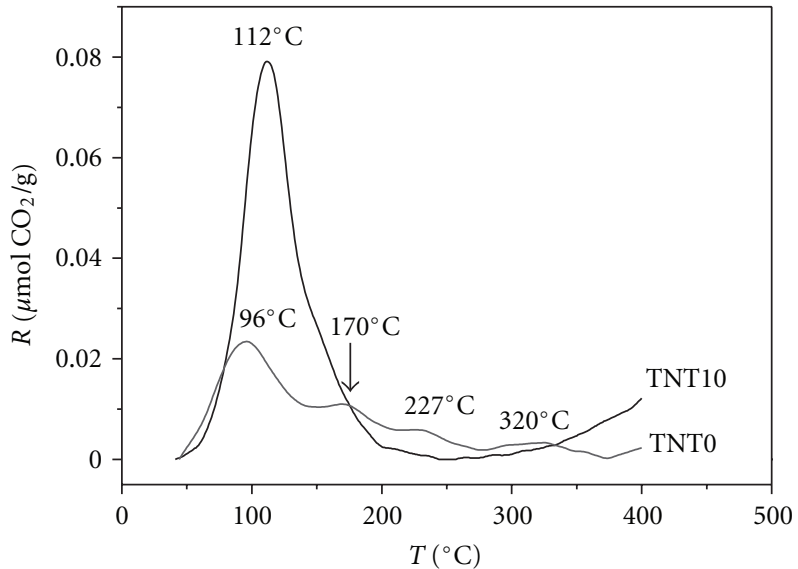

(d)

Figure 3: (a) Nitrogen adsorption-desorption isotherms, (b) BJH pore size distributions, (c) ammonia temperature-programmed desorption ( $\left.\mathrm{NH}_{3}-\mathrm{TPD}\right)$, and (d) carbon dioxide temperature-programmed desorption $\left(\mathrm{CO}_{2}-\mathrm{TPD}\right)$ for pristine (TNT10) and ion-exchanged (TNT0) titanate nanotubes.

area (see Table 1) of the protonated nanotubes TNT0 was about $200 \mathrm{~m}^{2} / \mathrm{g}$, while for pristine nanotubes TNT10, it was two times lower (about $100 \mathrm{~m}^{2} / \mathrm{g}$ ) (see Table 1). Figure 3(a) shows the trends of nitrogen adsorption-desorption isotherms. The hysteresis shape of adsorption-desorption curves in both of the cases corresponds to multilayer nitrogen adsorption. Both adsorption and desorption processes revealed no sharp steps on the isotherms that could be interpreted as a lack of well-fitted pore systems in both of the fractions of nanotubes. A specific pore volume $V_{p}$ of ion-exchanged TNT0 also exceeded remarkably the $V_{p}$ value for pristine material TNT10 (Table 1). Figure 3(b) illustrates the $V_{p}(R)-R$ distributions where $R$ is a pore radius.

The BJH model shows a wide distribution of pores for TNT10 and TNT0. The major pore volume originated from the pores with a diameter of $5.5-30 \mathrm{~nm}$, and the appearance of smaller pores of $1.2-12 \mathrm{~nm}$ in diameter was also predictable and, very likely, relates to the inner hollow spaces of the nanotubes. The less intensive maximum appears reproducibly for the isotherms, while the mean mesopore diameter is slightly larger for TNT10 that agrees with [13]. Both of the isotherms (Figure 3(a)) have a step at lowered pressures $\left(p / p_{0}\right.$ values) which corresponds to micropores.

Thus, the acid treatment of pristine nanotubes leads to an increase of the overall specific surface area of the material resulting in potentially better catalyst or a catalyst support. At the same time, the total pore volume grows up demonstrating reorganization processes in aggregates of nanotubes. Vice versa, a change of zeta potentials of the titania particles under an acid treatment provokes the formation of waterbased colloid solution producing less aggregated precipitates. Likely, this ion-exchange procedure also leads to an evolution of the nanotubular microstructures making their internal spaces available for adsorbate molecules.

It is known that titania nanotubes play a dual role in the catalysis [24] either acting as a high surface area material or modifying also the catalyst clusters due to a local chemical interaction. This makes it important to achieve given superficial properties of the nanotubes in terms of 
TABLE 2: Specific surface areas (BET); specific pore volumes $\left(V_{p}\right)$; ammonia and carbon dioxide adsorption capacities equal to total amounts of acid and base sited on TNT (from TPD- $\mathrm{NH}_{3}$ and TPD-CO $\mathrm{CO}_{2}$, resp.).

\begin{tabular}{lcccccc}
\hline Sample & $S_{\mathrm{BET}}, \mathrm{m}^{2} / \mathrm{g}$ & $V_{p}, \mu \mathrm{L} / \mathrm{g}$ & $a_{0} / \mathrm{m}, \mu \mathrm{mol} \mathrm{NH} / \mathrm{g}$ & $a_{0} / S, \mu \mathrm{mol} \mathrm{NH} / \mathrm{m}^{2}$ & $a_{0} / \mathrm{m}, \mu \mathrm{mol} \mathrm{CO} C_{2} / \mathrm{g}$ & $a_{0}, / S, \mu \mathrm{mol} \mathrm{CO}_{2} / \mathrm{m}^{2}$ \\
\hline TNT0_400 & $209 \pm 20$ & 0.81 & 271.3 & 0.022 & 2.6 & 0.012 \\
TNT10_400 & $107 \pm 10$ & 0.32 & $(0.2)$ & 0.002 & 5.1 & 0.048 \\
\hline
\end{tabular}

their acidity. TPD of ammonia and carbon dioxide let the characterization of acid/base properties of the materials. This technique makes it possible to estimate the total number of acid or base sites on the substrate surface [25]. The total adsorption capacities are given in Table 2.

Brønsted acid sites of titania are usually "stronger" than Lewis sites [26] and desorb ammonia above $400^{\circ} \mathrm{C}$ [27]. In the case of TNTs, this temperature is rather close to the recrystallization temperatures, and there is no chance to analyze the origin of these strong adsorption sites adequately. Theoretically, the high-temperature adsorption sites could be of both of the types, but mostly Brønsted acid sites are expected [25]. Topsoe et al. [28] demonstrated experimentally that titania adsorbs ammonia molecules predominantly on Lewis acid sites which supports the previous discussion.

According to Avgouropoulos and Ioannides [25], water molecules are able to displace basic probe molecules at Brønsted acid sites of the titania. Since the titanate nanotubes pretreated at $400^{\circ} \mathrm{C}$ lost structural water almost completely (see TG results), we could suggest that all the available adsorption sites are of the Lewis type acid sites of pure nanotubes. Such acid sites are $\mathrm{Ti}^{4+}$ and $\mathrm{Ti}^{3+}[27,29]$.

The total number of Lewis acid sites in the case of ionexchanged nanotubes (TNT0_400) is much higher than that of calcined pristine TNT10_400 (Table 2). Evidently, most of the available acid sites are occupied by sodium ions which prevent adsorption of bases. The TPD curve for the protonated fraction demonstrates two peaks of ammonia desorption (Figure 3(c)) at about $105 \pm 2{ }^{\circ} \mathrm{C}$ and $280 \pm 5^{\circ} \mathrm{C}$ which correspond to two kinds of Lewis acid sites. The less intensive peak should be associated with $\mathrm{Ti}^{3+}$ sites [29], while the more intensive one could be related to $\mathrm{Ti}^{4+}$ sites [30].

Carbon dioxide adsorption is more substantial in the case of the alkali fraction than of the protonated sample. To take into account a relationship between adsorption capacities of the materials and specific surface areas, we operated surface-normalized adsorption capacities given in Table 2. The surface-normalized adsorption capacity of TNT10_400 is about $0.05 \mu \mathrm{mol} \mathrm{CO} 2$ per $1 \mathrm{~m}^{2}$, while for TNT0_400, it is only $0.012 \mu \mathrm{mol} \mathrm{CO} 2 / \mathrm{m}^{2}$. The difference could be caused by sodium cations served as additional base sites which partly shield $\mathrm{Ti}^{4+}$ acid sites. Desorption of $\mathrm{CO}_{2}$ molecules from the alkali sites occurs only at about $500^{\circ} \mathrm{C}$ in parallel with the decomposition of the tubular structure forming sodium titanate. The total $\mathrm{CO}_{2}$ adsorption capacity of TNT10_400 matches roughly the number of $\mathrm{Na}^{+}$sites.

Intensive $\mathrm{CO}_{2}$ desorption occurs at about $100^{\circ} \mathrm{C}$ that correlates with characteristics of barium titanate given by Zhao et al. [31] and also of the Au/TNT catalyst reported by Ntho et al. [32]. In the case of TNT10_400, the maximum is rather sharp (Figure $3(\mathrm{~d})$ ). Most probably, this effect proceeds from larger pore size in TNT10_400, that is, the pore system of TNT0_400 delays signal registration because of internal diffusion of probe molecules.

Thus, adsorption and thermal stability characteristics of titanate nanotubes correlate with sodium content strongly. The low-temperature CO oxidation over titania nanotubes reported recently $[23,24]$ seems to be more typical for sodium contained samples than for the protonated fraction because the pristine nanotubes release $\mathrm{CO}_{2}$ easily and completely below $100^{\circ} \mathrm{C}$. The structure of the material is also different in the case of the protonated form and corresponds more to sodium trititanate than to trititanic acid. The protonated form is isostructural to trititanic acid, but some admixture of hydrated pentatitanate is possible. To obey a balance between chemical and heat treatments of the nanotubes to design their functional properties has been suggested.

\section{Experimental}

Nanotubular titania was synthesized as described elsewhere [33]. Polycrystalline anatase powder (SigmaAldrich, T8141, $99 \%$ ) was homogenized with $10 \mathrm{M} \mathrm{NaOH}$ aqueous solution for $1 \mathrm{~h}$, and then the reaction mixture was autoclaved in a special Teflon-lined cell at $180^{\circ} \mathrm{C}$ for $48 \mathrm{~h}$. One fraction of the nanotubes was divided and washed repeatedly with $0.1 \mathrm{M}$ $\mathrm{HNO}_{3}$ until $\mathrm{pH}=1$ with subsequent washing with pure water $(R=10 \mathrm{M} \Omega$ ) until $\mathrm{pH}$ reached 6 . Each of the two fractions was divided into three fractions and calcined in air at $120^{\circ} \mathrm{C}$, $200^{\circ} \mathrm{C}$, or $400^{\circ} \mathrm{C}$ for $2 \mathrm{~h}$ to remove adsorbed water. The list of all nanotubes fractions is given in Table 1.

The microstructure of the samples was studied using a transmission electron microscopy (Leo 912 AB Omega (Leo, Germany), $\mathrm{LaB}_{6}$ cathode, accelerating potential $100 \mathrm{kV}$ ). All the samples were examined by X-ray diffraction (XRD) using Rigaku D/MAX 2500 diffractometer (Japan) with a rotating copper anode $\mathrm{CuK} \alpha\left(2 \Theta\right.$ range of $5-80^{\circ}$ with a step of $0.02^{\circ}$ ). The thermal stability of materials was investigated using thermoanalyzer Pyris Diamond TG-DTA (PerkinElmer) (platinum crucibles; heating rate $5 \% \mathrm{~min}$; air).

The surface area, pore sizes, and pore size distribution were examined using nitrogen sorption using Nova 4200 e setup (Quantachrome Instruments). The adsorptiondesorption isotherms were used to estimate the specific surface area of the nanotubes according to the BrunauerEmmett-Teller approach (BET). The preheating temperature was $120^{\circ} \mathrm{C}$.

Temperature-programmed desorption experiments $\left(\mathrm{NH}_{3}-\mathrm{TPD}\right)$ were performed in a homework setup. Before the experiments, the samples were pretreated for $2 \mathrm{~h}$ at $400^{\circ} \mathrm{C}$ 
in a flow of helium. All $\mathrm{NH}_{3}$-adsorption experiments were carried out at ambient temperature in a flow of $\mathrm{NH}_{3}: \mathrm{N}_{2}=$ $1: 1$ gas mixture and after purging the sample in a helium flow at $50^{\circ} \mathrm{C}$ during $60 \mathrm{~min}$ to remove physiadsorbed ammonia. The temperature was increased by $8^{\circ} \mathrm{C} / \mathrm{min}$ up to $700^{\circ} \mathrm{C}$. The same experimental setup was applied in $\mathrm{CO}_{2}$ TPD experiments. The sample weights were $100 \pm 2 \mathrm{mg}$. All adsorption characteristics were analyzed using $0.25-0.5 \mathrm{~cm}$ granules of preliminary pressed nanotubes (35-55 mesh).

\section{Acknowledgments}

The authors are grateful to K. L. Dubova, T. V. Filippova, A. S. Vyacheslavov, K. S. Napolskii, and S. S. Abramchuk (Lomonosov Moscow State University). This project was supported by grants of Russian Federal Agency for Science and Innovations, the Russian Foundation of Basic Research (Project Nos. 10-03-00997-a, 11-03-12154-ofi-m-2011, and 12-03-00800-a), and Haldor Topsoe A/S. They acknowledge partial support from M. V. Lomonosov Moscow State University Program of Development.

\section{References}

[1] L. M. Bjursten, L. Rasmusson, S. Oh, G. C. Smith, K. S. Brammer, and S. Jin, "Titanium dioxide nanotubes enhance bone bonding in vivo," Journal of Biomedical Materials Research A, vol. 92, no. 3, pp. 1218-1224, 2010.

[2] D. V. Bavykin, J. M. Friedrich, and F. C. Walsh, "Protonated titanates and $\mathrm{TiO}_{2}$ nanostructured materials: synthesis, properties, and applications," Advanced Materials, vol. 18, no. 21, pp. 2807-2824, 2006.

[3] A. V. Grigorieva, E. A. Goodilin, K. L. Dubova et al., "Titania nanotubes, nanorods and nanopowder in the carbon monoxide oxidation process," Solid State Sciences, vol. 12, no. 6, pp. 1024-1028, 2010.

[4] Y. Tian, C. Hu, X. He, C. Cao, G. Huang, and K. Zhang, "Titania nanotube arrays for light sensor and UV photometer," Sensors and Actuators B, vol. 144, no. 1, pp. 203-207, 2010.

[5] H. H. Ou and S. L. Lo, "Review of titania nanotubes synthesized via the hydrothermal treatment: fabrication, modification, and application," Separation and Purification Technology, vol. 58, no. 1, pp. 179-191, 2007.

[6] G. F. Ortiz, I. Hanzu, T. Djenizian, P. Lavela, J. L. Tirado, and P. Knauth, "Alternative Li-ion battery electrode based on selforganized titania nanotubes," Chemistry of Materials, vol. 21, no. 1, pp. 63-67, 2009.

[7] P. Panagiotopoulou, A. Christodoulakis, D. I. Kondarides, and S. Boghosian, "Particle size effects on the reducibility of titanium dioxide and its relation to the water-gas shift activity of $\mathrm{Pt} / \mathrm{TiO}_{2}$ catalysts," Journal of Catalysis, vol. 240, no. 2, pp. 114-125, 2006.

[8] Q. Zhao, M. Li, J. Chu, T. Jiang, and H. Yin, "Preparation, characterization of $\mathrm{Au}$ (or Pt)-loaded titania nanotubes and their photocatalytic activities for degradation of methyl orange," Applied Surface Science, vol. 255, no. 6, pp. 37733778, 2009.

[9] E. Formo, E. Lee, D. Campbell, and Y. Xia, "Functionalization of electrospun $\mathrm{TiO}_{2}$ nanofibers with $\mathrm{Pt}$ nanoparticles and nanowires for catalytic applications," Nano Letters, vol. 8, no. 2, pp. 668-672, 2008.
[10] X. B. Ke, H. Y. Zhu, X. P. Gao, J. W. Liu, and Z. F. Zheng, "High-performance ceramic membranes with a separation layer of metal oxide nanofibers," Advanced Materials, vol. 19, no. 6, pp. 785-790, 2007.

[11] S. Zhang, J. Zhou, Z. Zhang, Z. Du, A. V. Vorontsov, and Z. Jin, "Morphological structure and physicochemical properties of nanotube $\mathrm{TiO}_{2}$," Chinese Science Bulletin, vol. 45, no. 16, pp. 1533-1536, 2000.

[12] C. C. Tsai, J. N. Nian, and H. Teng, "Mesoporous nanotube aggregates obtained from hydrothermally treating $\mathrm{TiO}_{2}$ with NaOH," Applied Surface Science, vol. 253, no. 4, pp. 1898-1902, 2006.

[13] C. C. Tsai and H. Teng, "Regulation of the physical characteristics of titania nanotube aggregates synthesized from hydrothermal treatment," Chemistry of Materials, vol. 16, no. 22, pp. 4352-4358, 2004.

[14] S. Zhang, L. M. Peng, Q. Chen, G. H. Du, G. Dawson, and W. Z. Zhou, "Formation Mechanism of $\mathrm{H}_{2} \mathrm{Ti}_{3} \mathrm{O}_{7}$ Nanotubes," Physical Review Letters, vol. 91, no. 25, pp. 2561031-2561034, 2003.

[15] J. Yang, Z. Jin, X. Wang et al., "Study on composition, structure and formation process of nanotube $\mathrm{Na}_{2} \mathrm{Ti}_{2} \mathrm{O}_{4}(\mathrm{OH})_{2}$," Dalton Transactions, no. 20, pp. 3898-3901, 2003.

[16] R. Ma, Y. Bando, and T. Sasaki, "Nanotubes of lepidocrocite titanates," Chemical Physics Letters, vol. 380, no. 5-6, pp. 577582, 2003.

[17] C. C. Tsai and H. Teng, "Structural features of nanotubes synthesized from $\mathrm{NaOH}$ treatment on $\mathrm{TiO}_{2}$ with different post-treatments," Chemistry of Materials, vol. 18, no. 2, pp. 367-373, 2006.

[18] D. Wu, J. Liu, X. Zhao, A. Li, Y. Chen, and N. Ming, "Sequence of events for the formation of titanate nanotubes, nanofibers, nanowires, and nanobelts," Chemistry of Materials, vol. 18, no. 2, pp. 547-553, 2006.

[19] C. C. Tsai, J. N. Nian, and H. Teng, "Mesoporous nanotube aggregates obtained from hydrothermally treating $\mathrm{TiO}_{2}$ with NaOH," Applied Surface Science, vol. 253, no. 4, pp. 1898-1902, 2006.

[20] H. Tokudome and M. Miyauchi, "Titanate nanotube thin films via alternate layer deposition," Chemical Communications, vol. 10, no. 8, pp. 958-959, 2004.

[21] L. Miao, Y. Ina, S. Tanemura et al., "Fabrication and photochromic study of titanate nanotubes loaded with silver nanoparticles," Surface Science, vol. 601, no. 13, pp. 27922799, 2007.

[22] Z. R. Tian, J. A. Voigt, J. Liu, B. McKenzie, and H. Xu, "Large oriented arrays and continuous films of $\mathrm{TiO}_{2}$-based nanotubes," Journal of the American Chemical Society, vol. 125, no. 41, pp. 12384-12385, 2003.

[23] R. Camposeco, S. Castillo, I. Mejia et al., "Active $\mathrm{TiO}_{2}$ nanotubes for CO oxidation at low temperature," Catalysis Communications, vol. 17, pp. 81-88, 2012.

[24] A. V. Grigorieva, E. A. Goodilin, L. E. Derlyukova et al., "Titania nanotubes supported platinum catalyst in $\mathrm{CO}$ oxidation process," Applied Catalysis A, vol. 362, no. 1-2, pp. 20-25, 2009.

[25] G. Avgouropoulos and T. Ioannides, "TPD and TPSR study of $\mathrm{CO}$ interaction with $\mathrm{CuO}-\mathrm{CeO}_{2}$ catalysts," Journal of Molecular Catalysis A, vol. 296, no. 1-2, pp. 47-53, 2008.

[26] A. P. Kulkarni and D. S. Muggli, "The effect of water on the acidity of $\mathrm{TiO}_{2}$ and sulfated titania," Applied Catalysis A, vol. 302, no. 2, pp. 274-282, 2006.

[27] M. A. Reiche, E. Ortelli, and A. Baiker, "Vanadia grafted on $\mathrm{TiO}_{2}-\mathrm{SiO}_{2}, \mathrm{TiO}_{2}$ and $\mathrm{SiO}_{2}$ aerogels: structural properties and 
catalytic behaviour in selective reduction of $\mathrm{NO}$ by $\mathrm{NH}_{3}$," Applied Catalysis B, vol. 23, no. 2-3, pp. 187-203, 1999.

[28] N. Y. Topsoe, H. Topsoe, and J. A. Dumesic, "Vanadia/titania catalysts for selective catalytic reduction (SCR) of nitricoxide by ammonia: I. Combined temperature programmed in situ FTIR and on-line mass-spectroscopy studies," Journal of Catalysis, vol. 151, no. 1, pp. 226-240, 1995.

[29] G. Lu, A. Linsebigler, and J. T. Yates, " $\mathrm{Ti}^{3+}$ defect sites on $\mathrm{TiO}_{2}(110)$ : production and chemical detection of active sites," Journal of Physical Chemistry, vol. 98, no. 45, pp. 11733-11738, 1994.

[30] M. E. Manríquez, T. López, R. Gómez, and J. Navarrete, "Preparation of $\mathrm{TiO}_{2}-\mathrm{Zr}$," Journal of Molecular Catalysis A, vol. 220, pp. 229-237, 2004.

[31] M. H. Zhao, D. A. Bonnell, and J. M. Vohs, "Effect of ferroelectric polarization on the adsorption and reaction of ethanol on $\mathrm{BaTiO}_{3}$," Surface Science, vol. 602, no. 17, pp. 2849 $2855,2008$.

[32] T. A. Ntho, J. A. Anderson, and M. S. Scurrell, "CO oxidation over titanate nanotube supported Au: deactivation due to bicarbonate," Journal of Catalysis, vol. 261, no. 1, pp. 94-100, 2009.

[33] W. Wang, J. Zhang, H. Huang, Z. Wu, and Z. Zhang, "Surfacemodification and characterization of $\mathrm{H}$-titanate nanotube," Colloids and Surfaces A, vol. 317, no. 1-3, pp. 270-276, 2008. 

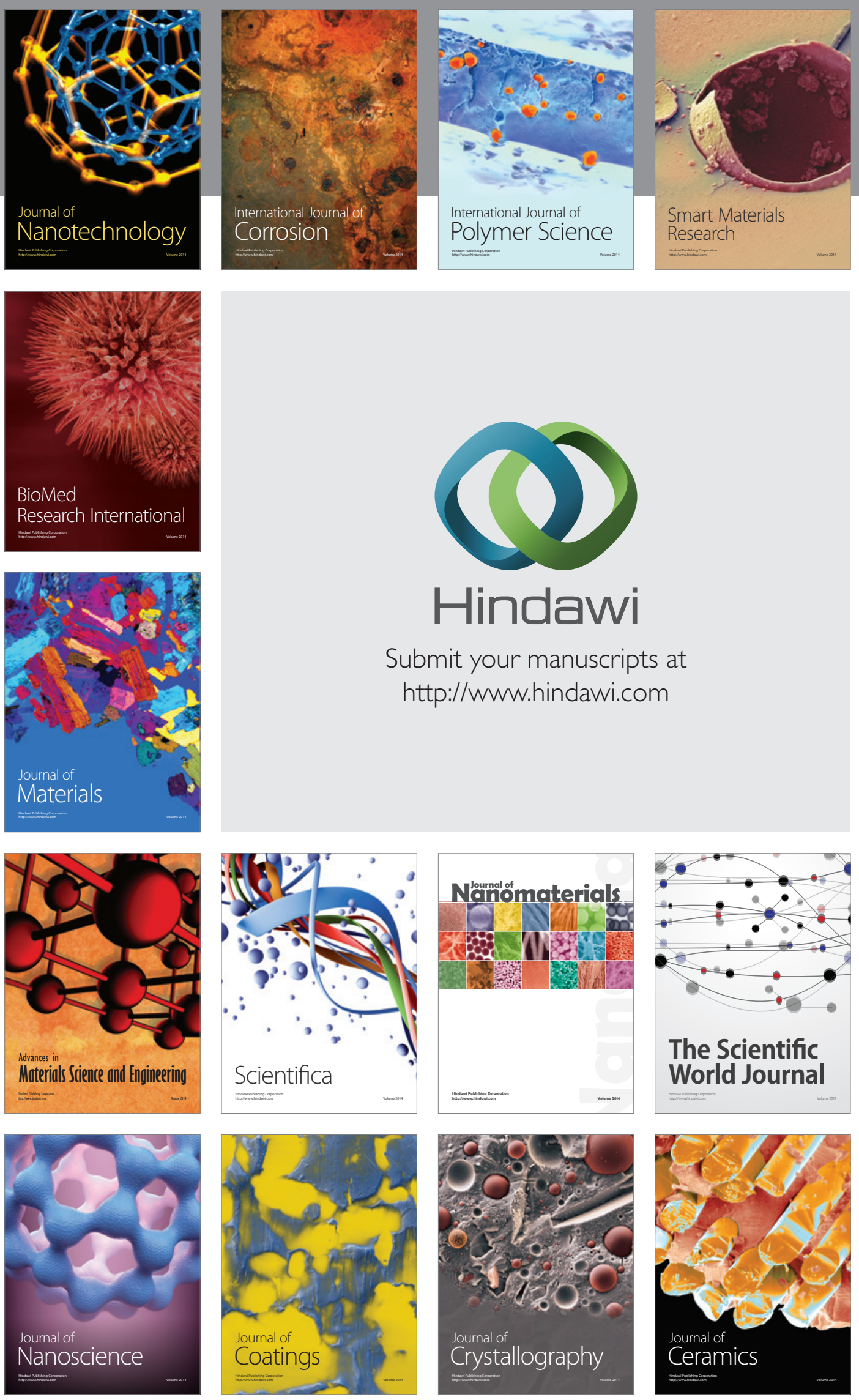

The Scientific World Journal

Submit your manuscripts at

http://www.hindawi.com

\section{World Journal}

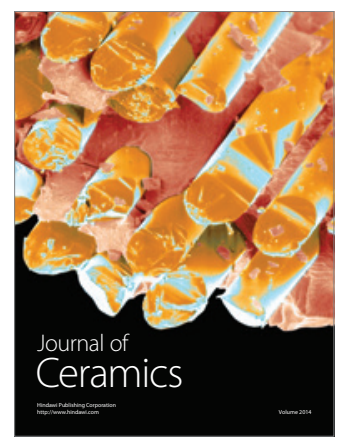

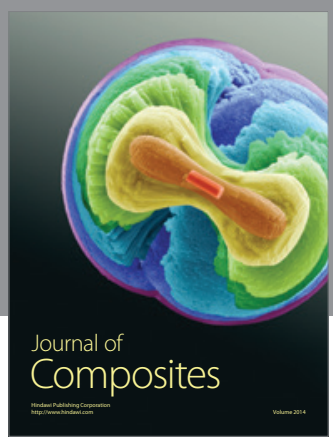
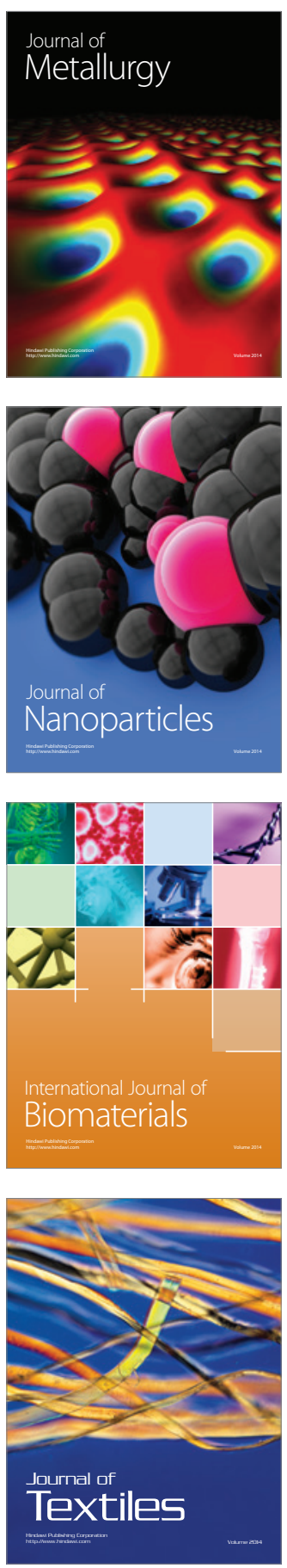